Classification

Physics Abstracts

$61.00-61.50 \mathrm{~K}$

\title{
On heterogeneous crystalline compounds and the phasoid concept
}

\author{
Arne Magnéli \\ Department of Inorganic Chemistry, Arrhenius Laboratory, University of Stockholm, \\ S-106 91 Stockholm, Sweden
}

(Received October 29, 1990; accepted February 22, 1991)

\begin{abstract}
Résumé. - Le concept de phasoïde a été introduit pour décrire l'ensemble de structures similaires qui coexistent dans les structures à intercroissance dans les bronzes de tungstène préparées sous des conditions expérimentales normales. Il constitue un moyen pratique pour décrire des systèmes compliqués, comme les oxydes de métaux de transition qui présentent des intercroissances d'unités structurales simples ou des cisaillements cristallographiques. De tels systèmes conduisent souvent à l'existence d'arrangements hétérogènes de structures hors d'équilibre et qui résistent aux traitements thermiques d'homogénéisation.
\end{abstract}

\begin{abstract}
The phasoid concept was introduced to describe the ensemble of closely related structures which under normal preparative conditions coexist in samples of intergrowth tungsten bronzes. It provides a useful means to treat complicated systems in a manageable way, e.g. transition metal oxides which contain intergrowths of simple structural units or crystallographic shear. Such systems often form heterogeneous non-equilibrium products, which are resistent to homogenization by thermal treatment.
\end{abstract}

High resolution electron microscopy (HREM) studies by Svensson[1] of ternary niobium oxide systems with barium, strontium and potassium have revealed the existence of a variety of structures, which can be described as intergrowths of $\mathrm{NbO}$ - and $A \mathrm{NbO}_{3}$ (perovskite-type) elements. One-dimensional lamellar intergrowth of slabs of $\mathrm{NbO}$ and $A \mathrm{NbO}_{3}$ is present in the ordered stoichiometric phases $\mathrm{Ba}_{2} \mathrm{Nb}_{5} \mathrm{O}_{9}$ and $\mathrm{Sr}_{2} \mathrm{Nb}_{5} \mathrm{O}_{9}$. A similar structure in the potassium system, $\mathrm{KNb}_{4} \mathrm{O}_{6}$, often contains defects, viz. perovskite slabs of deviating widths.

Very different from the HREM pictures of these ordered or moderately disordered structures are those given by barium and strontium samples containing two-dimensional intergrowths of $\mathrm{NbO}$ and $\mathrm{ANbO}_{3}$. The micrograph of such a sample is shown in figure 1. In the highly disordered pattern there are small domains which show some degree of ordering of differing kinds, and these may be discussed in terms of microphases and associated with various homologous series. However, attempts to obtain samples with ordered structures by prolonged heating have been unsuccessful. The material is therefore characterized as a phasoid.

The concept phasoid [2] was introduced to describe the so-called intergrowth tungsten bronzes, 


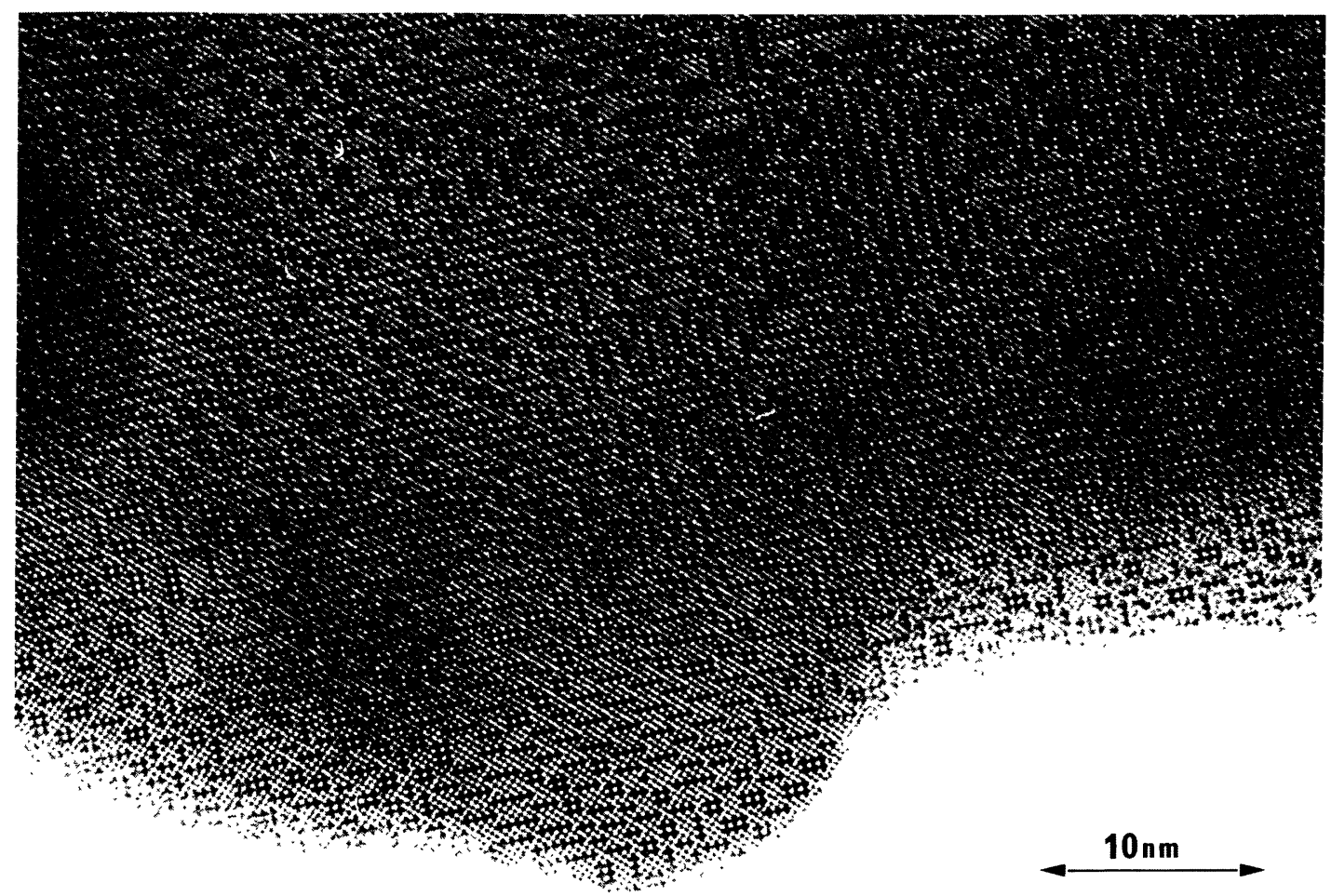

Fig. 1. - HREM image of $\alpha$-phasoid in sample of gross composition $\mathrm{BaNb}_{6} \mathrm{O}_{8}$. The dark contrast corresponds to $\mathrm{Nb}_{6}$ octahedra of $\mathrm{NbO}$; the square net in between represents the $\mathrm{Ba}$ and $\mathrm{Nb}$ atoms of perovskite.

ITB [3]. The building principle of these compounds $A_{x} \mathrm{WO}_{3}(A=\mathrm{K}$ and heavier alkali metals, $x \leq 0.1$ ) is a lamellar intergrowth of slabs of hexagonal tungsten bronze type (HTB), which contain the $A$ atoms, with slabs of distorted $\mathrm{WO}_{3}$ structure (Fig. 2). By varying the thickness of the slabs it is possible to derive homologous series of ideally ordered ITB structures. Such ordered structures have been observed but are exceptional, however. Even carefully prepared samples, when examined by HREM, show a high degree of structural disorder, with slabs of very different widths (Fig. 3). Heat treatment extending over periods of months does not usually result in ordered single-phase samples, although the degree of order in individual crystallites may have increased. A state of thermodynamic equilibrium thus not being practically attainable, it appeared useful to introduce the word phasoid to describe the ensemble of ITB structures in the system. In the diagram of conditions for formation of potassium tungsten bronzes (Fig. 4), the areas HTB and TTB (for tetragonal tungsten bronze) represent phases of variable compositions, the variations being associated with the occurrence of point defects (vacancies) at the potassium atom positions. The ITB area, on the other hand, indicates the range of temperatures and compositions within which the phasoid materials form.

The phasoid concept should be useful in describing in a manageable way, structures and conditions of formation in many other kinds of complex systems, e.g. transition metal oxide systems which exhibit crystallographic shear (CS). If once formed at irregular spacings, which is very often the case, CS planes are not likely to move laterally even at prolonged heat treatment, and a state of thermodynamic equilibrium is then not practically attainable. This is so e.g. in the tungsten 


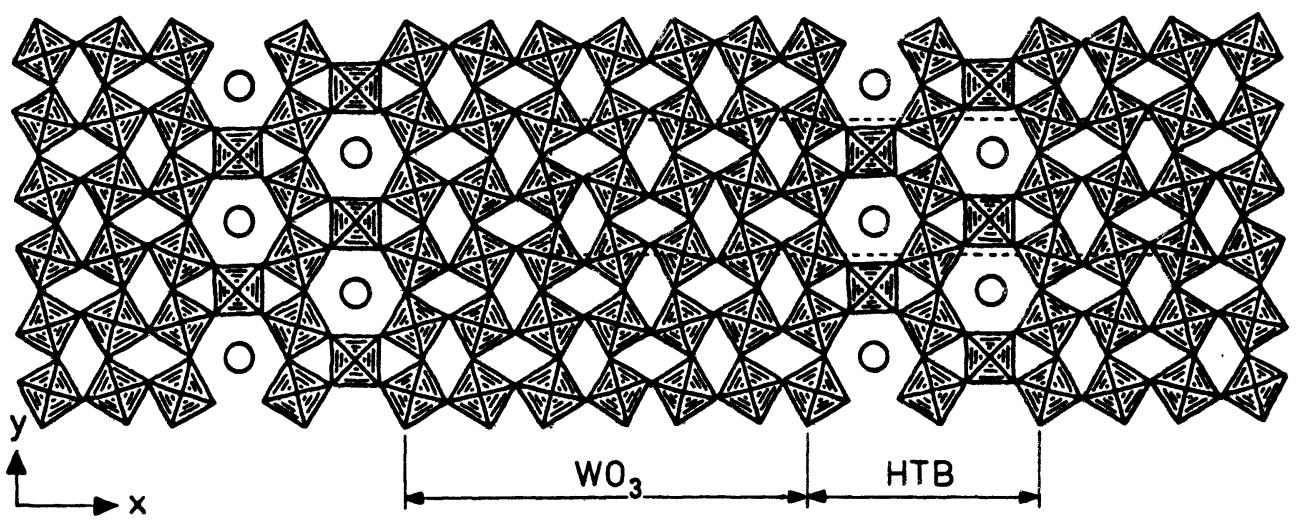

Fig. 2. - Structure model of an ITB phase (L. Kihlborg).

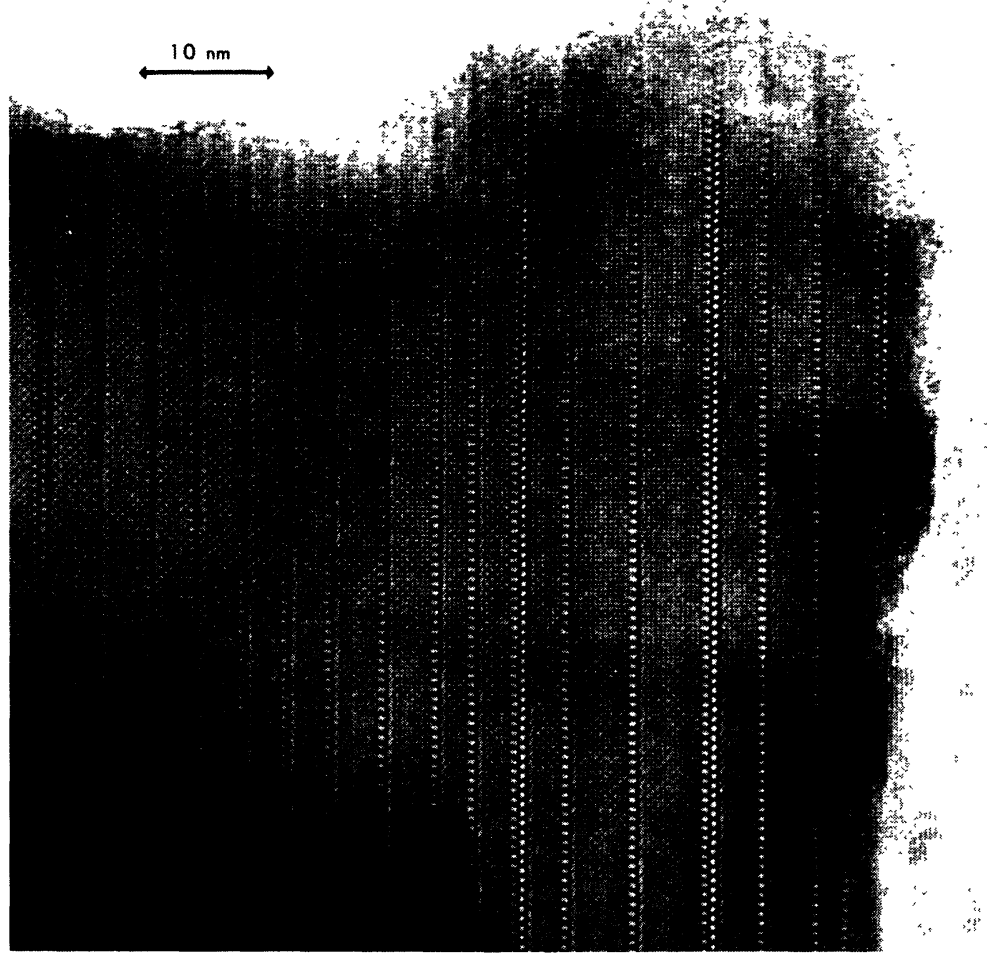

Fig. 3. - HREM image of an ITB crystallite from a $\mathrm{Cs}_{0.03} \mathrm{WO}_{3}$ sample. From [4].

oxide system ( 2 and references therein).

Crystalline compound materials which contain phasoid structures like those shown in figures 1 and 3 deviate much from the usual notion of chemicai compounds and wystals as homogeneous, periodic arrangements of atoms. Such heterocrystals ana heterocompounus, obtained by practical 


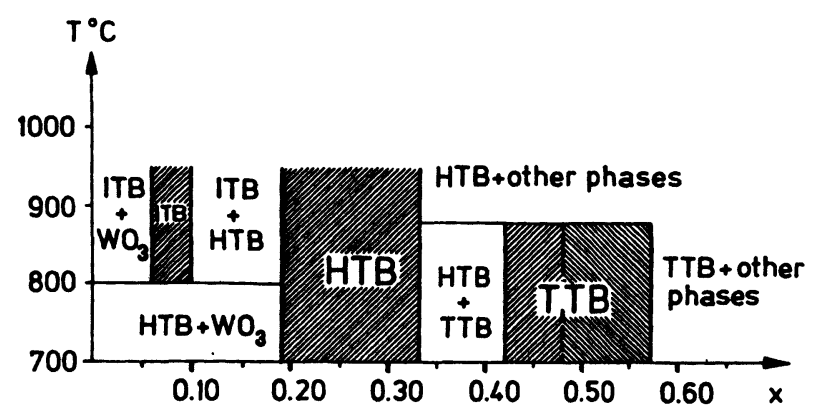

Fig. 4. - Diagram of conditions of formation of potassium tungsten bronzes, $K_{x} \mathrm{WO}_{3}$. From [5].

experiments or available in nature, obviously can show considerable local variations on the atomic level with respect to both structure and chemical composition.

\section{References}

[1] SVENSSON G., Microsc. Microanal. Microstruct. 1 (1991) 343.

[2] Magnéli A., Chem. Scr. 26 (1986) 535.

[3] Hussain A. and KinlbORg L., Acta Crystallogr. A32 (1976) 551.

[4] Kinlborg L., Chem. Scr. 14 (1978-79) 187.

[5] Hussain A., Acta Chem. Scand. A32 (1978) 479. 